
Not for reproduction, distribution or commercial use.

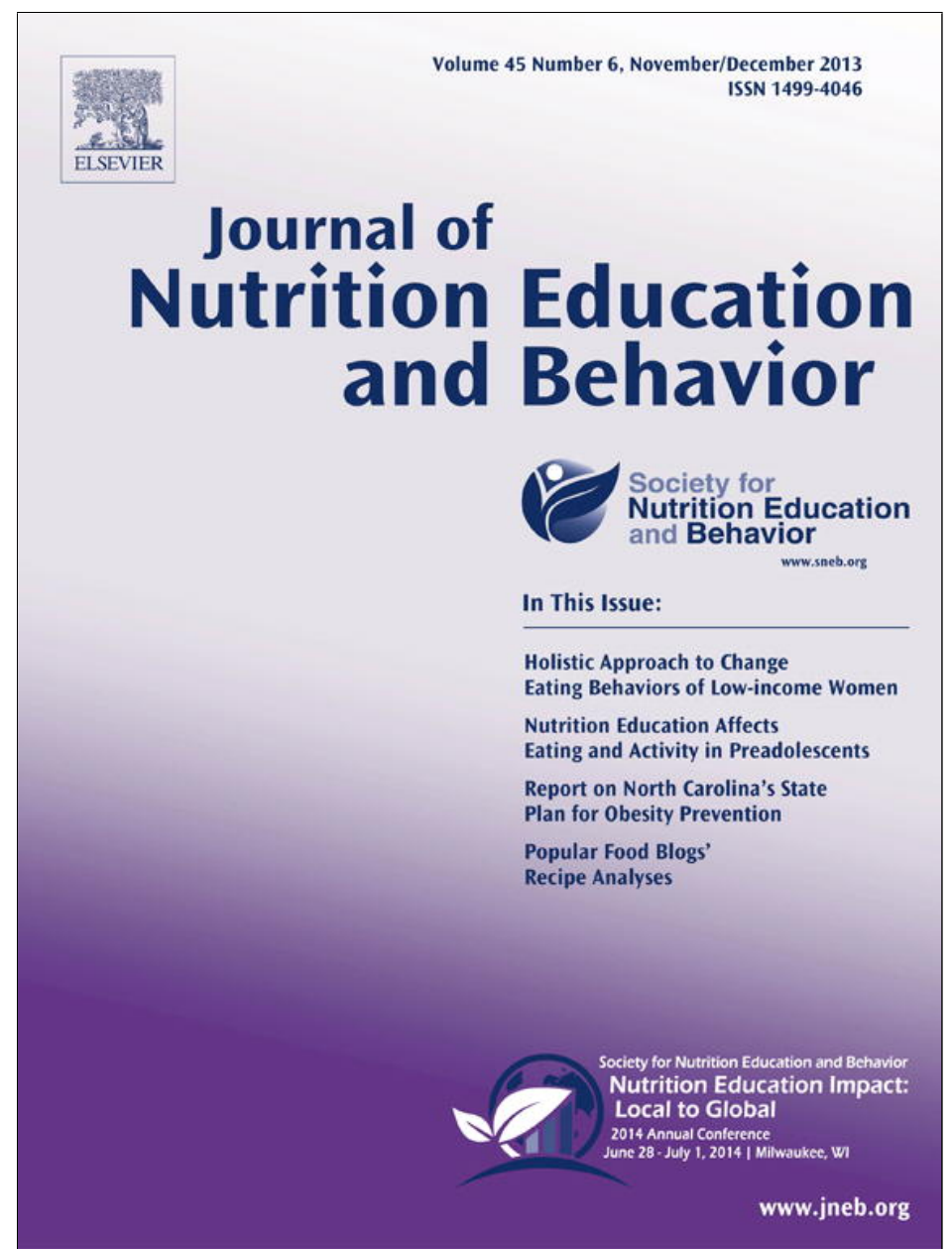

This article appeared in a journal published by Elsevier. The attached copy is furnished to the author for internal non-commercial research and education use, including for instruction at the authors institution and sharing with colleagues.

Other uses, including reproduction and distribution, or selling or licensing copies, or posting to personal, institutional or third party websites are prohibited.

In most cases authors are permitted to post their version of the article (e.g. in Word or Tex form) to their personal website or institutional repository. Authors requiring further information regarding Elsevier's archiving and manuscript policies are encouraged to visit: 


\title{
Sociodemographic Differences in the Comprehension of Nutritional Labels on Food Products
}

\author{
Sarah Sinclair, BSc; David Hammond, PhD; Samantha Goodman, MSc
}

\begin{abstract}
Objective: To examine comprehension of nutrition labels across sociodemographic groups using a measure of health literacy.

Methods: Cross-sectional survey of a community sample of adults including an adapted version of the Newest Vital Sign for Canadian Nutrition Facts table on prepackaged grocery products, including numerical conversion questions for calorie content and percent daily value.

Results: Approximately two thirds of participants were able to correctly identify calorie content and percent daily value from the nutrition label. Participants with higher education and higher income, those aged $\leq 64$ years, and those who look at nutritional facts or calories were significantly more likely to estimate the correct calorie content. Participants were significantly more likely to correctly identify percent daily value if they reported higher education, higher income, and white ethnicity.

Conclusions and Implications: Approximately one third of participants could not comprehend basic information on Canadian nutrition labels. Lower socioeconomic status was associated with poorer performance.
\end{abstract}

Key Words: nutrition labeling, food labels, health literacy, nutrition policy (J Nutr Educ Behav. 2013;45:767-772.)

\section{INTRODUCTION}

Global rates of overweight and obesity have been increasing in recent years. As of 2008, there were 1.5 billion overweight adults worldwide, or one tenth of the world population. ${ }^{1}$ In Canada, obesity has risen from 14\% in 1992 to nearly one quarter of the population, primarily as the result of increased calorie intake and decreased physical activity. ${ }^{2}$

Since 2007, nutrition labels have been mandatory on almost all prepackaged foods in Canada. ${ }^{3}$ Nutrition labels are the primary source of nutrition information for many Canadians. ${ }^{4-7}$ The use of nutrition labels has been associated with healthier dietary choices with respect to calories, fat, and nutrients, at least in part because of greater use among more health-conscious individuals and those of higher socioeconomic status. ${ }^{5,7}$
Most Canadians report a high level of confidence in both the credibility of nutrition information on labels and their ability to find all of the information they require to make healthier food choices. ${ }^{8}$ Despite widespread use and high levels of confidence among Canadians, there is evidence that many have difficulty understanding and applying the nutrition information. ${ }^{4,6,9}$ Difficulties with serving sizes and converting nutrient amounts are particularly apparent in older adults and people with lower education and income. $^{4-6}$ Thus, although Canadians consider themselves knowledgeable with respect to labels, they may not fully understand how many calories they have consumed based on serving size information.

Health literacy is defined as "the degree to which individuals have the capacity to obtain, process, and understand basic health information needed to make health decisions." ${ }^{10}$ Weiss

\footnotetext{
School of Public Health \& Health Systems, University of Waterloo, Waterloo, Ontario, Canada

Address for correspondence: David Hammond, PhD, School of Public Health \& Health Systems, University of Waterloo, 200 University Ave West, Waterloo, Ontario N2L 3G1, Canada; Phone: (519) 888-4567 ext 36462; Fax: (510) 886-6424; E-mail: dhammond@uwaterloo.ca

C2013 SOCIETY FOR NUTRITION EDUCATION AND BEHAVIOR

http://dx.doi.org/10.1016/j.jneb.2013.04.262
}

et $\mathrm{al}^{10}$ introduced the Newest Vital Sign (NVS) instrument as a health literacy tool in response to evidence that nearly $50 \%$ of Americans lacked basic health literacy. The NVS assesses numeracy and comprehension skills through 6 questions corresponding to the nutrition label for an ice cream container. ${ }^{10}$ Initial research on the NVS found adequate internal reliability, good sensitivity, and less than optimal specificity with respect to health literacy; however, only a limited number of studies have made use of the tool. ${ }^{10}$ The NVS has been compared with other health literacy tools, such as the Rapid Estimate of Health Literacy in Adults and the Test of Functional Health Literacy in Adults, and the evidence suggests that the NVS has a high sensitivity for detecting literacy. ${ }^{11}$

To the researchers' knowledge, no other studies have administered the NVS tool among Canadian populations. The primary objective of the current study was to assess the health literacy of individuals with respect to their understanding of calories and percent daily value on food labels using numeracy questions from an adapted NVS tool. The study also sought to examine potential differences among sociodemographic factors, and to increase the literature on the NVS within a Canadian context. 


\section{METHODS}

\section{Sample}

Participants for the study were 639 adults, aged $\geq 18$ years, from the Kitchener-Waterloo region. Participants were recruited for the study through newspaper, bus, and online advertisements, as well as advertisements at local markets in the region. The study was advertised as a "lifestyles" survey in the Waterloo region, to decrease potential self-selection bias. The Office of Research Ethics at the University of Waterloo granted ethics approval.

\section{Protocol}

The current study was a part of a larger study that examined the efficacy of nutrition information on menus and prepackaged grocery products. The full study protocol has been published elsewhere. ${ }^{12}$ Briefly, interested persons were screened over the telephone to determine eligibility. The questionnaire was administered with groups of up to 10 subjects at a time. During the first part of the study session, participants were randomly assigned to view menus with different types of nutrition information and provided with a free meal from Subway restaurant. Once subjects chose their free Subway meal, they performed an interim task in which they answered a questionnaire regarding city planning and healthy lifestyles in the Region of Waterloo. Participants then completed a survey on diet, lifestyle, and sociodemographics, as well as 2 of the 6 questions found in the original NVS that were specifically related to numeracy and conversion skills related to use of calorie information. The NVS measures for calorie labeling were selected given that calories are the most common source of information sought out by consumers in prepackaged food labeling, and given the central role of calorie amounts in restaurant menu labeling policies that are increasing in prominence. Figure 1 displays the nutritional label that was shown to participants. Once participants completed the questionnaire, a research assistant privately recorded their height and weight to

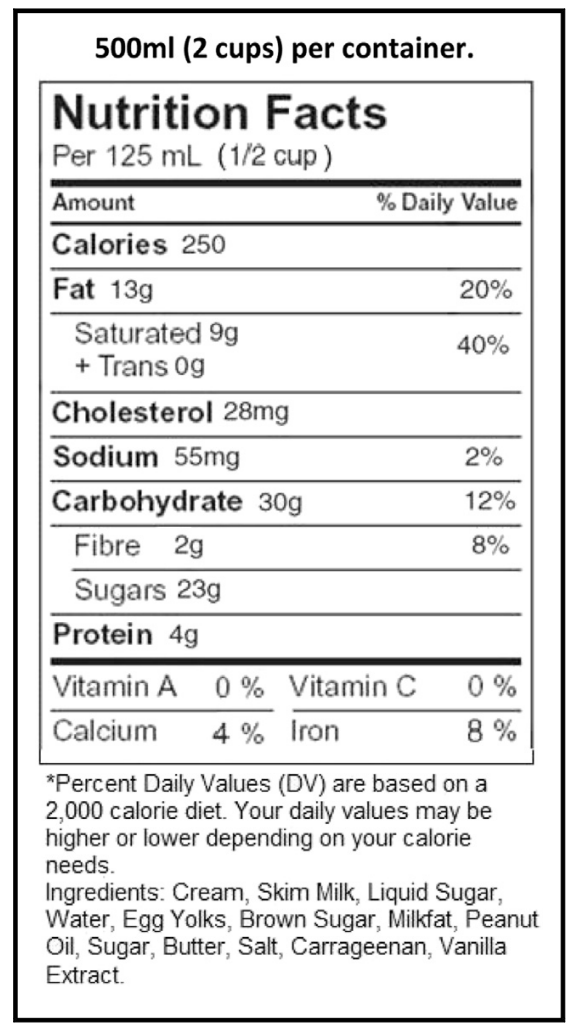

Figure 1. Nutritional label provided to participants to answer NVS adapted questions.

determine body mass index (BMI). Participants were then debriefed on the study and given a debriefing letter as well as \$20 remuneration.

\section{Measures}

Questionnaire demographics were analyzed as follows: age, in years $(1=18$ $24 ; 2=25-34 ; 3=35-64 ;$ and $4=\geq$ $65)$, gender $(1=$ male; and $2=$ female $)$, education ( 1 = low; some elementary school or less, some high school, or completed high school; 2 = middle; some college or university, or completed college or university; and $3=$ high; graduate or professional school), household income before taxes $(1=<$ $\$ 39,999 ; 2=\$ 40,000-\$ 79,999 ; 3=\geq$ $\$ 80,000$; and $4=$ preferred not to say), ethnicity $(1=$ white/Caucasian; and 2 $=$ other ethnicity), and BMI ( $1=$ underweight $[<18.5] ; 2=$ normal weight [18.5-24.9]; $3=$ overweight [25-29.9], and $4=$ obese [ $>30]$ ). Weight categories used were based on Health Canada's guidelines. ${ }^{13}$

Questions on label use and understanding were grouped together from the original questionnaire for analysis. The questions were coded and analyzed as: frequency of reading labels $(1=$ "Never/Only the first time I buy a product/sometimes"; 2 = "Usually/always") and types of nutrition information looked at $(1=$ none; $2=$ nutrition facts table or number of calories; and $3=$ any of the other nutrition information).

The questionnaire also collected data on 2 of the original 6 questions from the NVS tool developed by Weiss et al. $^{10}$ Participants were shown a nutrition label for a container of ice cream and asked the NVS calorie calculation question: "If you eat half the container of ice cream, how many calories will you eat? If you are unsure, please try to provide your best guess" ( $1=\ldots$ calories; $2=\mathrm{Do}$ not know). Responses were coded as 1 = "correct" (500 calories), and 2 = "incorrect" (do not know/any number other than 500). Participants were also asked the NVS percent daily value (\% DV) question: "If you usually eat 2,500 calories in a day, what percentage of your daily value of calories will you be eating if you eat 1 serving $(125 \mathrm{~mL})$ of ice cream? If you are unsure, please try to answer the question" (1 = \% DV; $2=$ Do not know). Responses were coded as 1 = "correct" (10\% DV), 2 = "incorrect" (Do not know/any number other than 10\%). The NVS \% DV question was also analyzed, allowing for responses to be $5 \%$ above or below the correct answer: NVS \% DV calculation $\pm 5(1=5 \%-15 \%$ DV [10\% DV, \pm $5 \%$ ]; $2=$ Do not know/any number aside from 5\%-15\%]. The original NVS tool was administered orally; however, in the current study, it was completed through a selfadministered questionnaire.

Questions on other health measures were combined for the analysis. Other health measures were coded and analyzed as: self-rated diet $(1=$ poor/fair/average; 2 = good/excellent), self-rated health $(1=$ poor/fair/ good; 2 = very good/excellent), and self-rated knowledge of health and nutrition issues $(1=$ strongly disagree/disagree somewhat/neutral/no opinion; 2 = agree somewhat/ strongly agree) based on the survey statement, "I am knowledgeable about health and nutrition issues." 


\begin{abstract}
Analysis
All analyses were conducted using SPSS statistical software, version 20.0 (IBM, Illinois, 2011). Two logistic regression models were conducted. The first model examined correlates of correctly calculating calorie amounts (where $1=$ incorrect and $2=$ correct). The second model examined correlates of correctly calculating the \% DV question (where $1=$ incorrect and $2=$ correct). Both models were run in two blocks or steps. The first block included core sociodemographic variables, including gender, age, education, income, ethnicity, and BMI. The second block included a set of more exploratory variables: frequency of reading labels, types of nutrition information looked at, selfrated diet, self-rated health, and selfrated health knowledge. A total of 23 participants were excluded from the analysis because of missing data.
\end{abstract}

\section{RESULTS}

\section{Sample Characteristics}

Table 1 presents the sample characteristics. Half of the participants were of normal weight according to the BMI categories; over half of the sample was in the overweight and obese categories.

\section{Newest Vital Sign Measures}

Figure 2 shows the proportion of people who correctly answered the adapted NVS question about calories, based on the ice cream nutrition facts table. All except 9 participants provided an estimate; these 9 participants were integrated with the incorrect responses. Overall, over $70 \%$ of respondents correctly estimated the calorie content (ie, 500 calories). Of those who answered incorrectly, the most common responses given were 125 calories $(\mathrm{n}=$ $71), 250$ calories $(\mathrm{n}=33)$, and 1,000 calories $(\mathrm{n}=50)$.

Figure 2 shows the proportion of participants who correctly and incorrectly answered the \% DV question. Correct answers were defined as $10 \%$ DV. A total of 41 participants selected the "Do not know" option and were integrated with the category of incorrect response. Overall, $66 \%$ of respondents correctly estimated the \% DV.
Table 1. Sociodemographic Data for Participants in Kitchener-Waterloo $(n=639)$

\begin{tabular}{ll} 
& \multicolumn{1}{c}{$\% \mathbf{( n )}$} \\
\hline Sex & \\
Male & $44.9(287)$ \\
Female & $55.1(352)$ \\
Age, y & \\
Mean & $44.7(\mathrm{SD}, 18.0)$ \\
18-24 & $19.2(123)$ \\
25-34 & $16.3(104)$ \\
35-64 & $48.4(309)$ \\
$\geq 65+$ & $16.1(103)$ \\
\hline Education & \\
Low & $16.9(108)$ \\
Middle & $64.6(413)$ \\
High & $18.5(118)$ \\
Income & \\
S \$39,999 & $36.9(236)$ \\
\$40,000-\$79,999 & $27.7(177)$ \\
$\geq \$ 80,000$ & $21.6(138)$ \\
Prefer not to say & $13.8(88)$ \\
\hline Ethnicity & \\
White & $71.5(457)$ \\
Other & $28.5(182)$ \\
Body mass index & \\
Underweight & $1.6(10)$ \\
Normal weight & $42.1(269)$ \\
Overweight & $32.4(207)$ \\
Obese & $23.9(153)$ \\
\hline
\end{tabular}

Of those who answered incorrectly, the most common estimates were $5 \%(\mathrm{n}=58)$ and $20 \%(\mathrm{n}=52)$.

\section{Correlates of NVS Measures}

Table 2 shows the results of the logistic regression examining the association between demographic variables and correct responses to the NVS calorie question. The sociodemographic predictor variables were run in 1 block in a logistical regression analysis. Age, education, and income were significantly associated with correctly answering the calorie question. Younger adults (specifically, those aged 18$24,25-34$, and 35-64 years) were significantly more likely to answer the calorie question correctly vs individuals aged $\geq 65$ years. Those aged 25 34 years were significantly more likely to get the answer correct vs participants aged 35-64 years. In addition, those aged 18-24 years were significantly more likely to answer the question correctly vs those aged 35-64 years. With respect to education, participants in the middle and high education levels were significantly more likely to answer the calorie question correctly vs participants in the lower education level. Higher income was also associated with correct responses; specifically, those who had a household income between $\$ 40,000$ and $\$ 79,999$, and $\geq \$ 80,000$ were significantly more likely to correctly answer the NVS calorie question than those who had an income of $\leq \$ 39,999$. Also, participants who had an income of $\geq \$ 80,000$ were significantly more likely to answer the calorie question correctly vs participants who did not indicate their income. No significant differences were observed for gender, ethnicity, or BMI.

When frequency of reading labels, types of nutrition information, selfrated diet, self-rated health, and self-rated knowledge of health and nutrition issues were added as a second block to the logistic regression, education was no longer significantly associated with answering the calorie question correctly $(P=.13)$. Of the covariates in the second block, type of information looked at was the

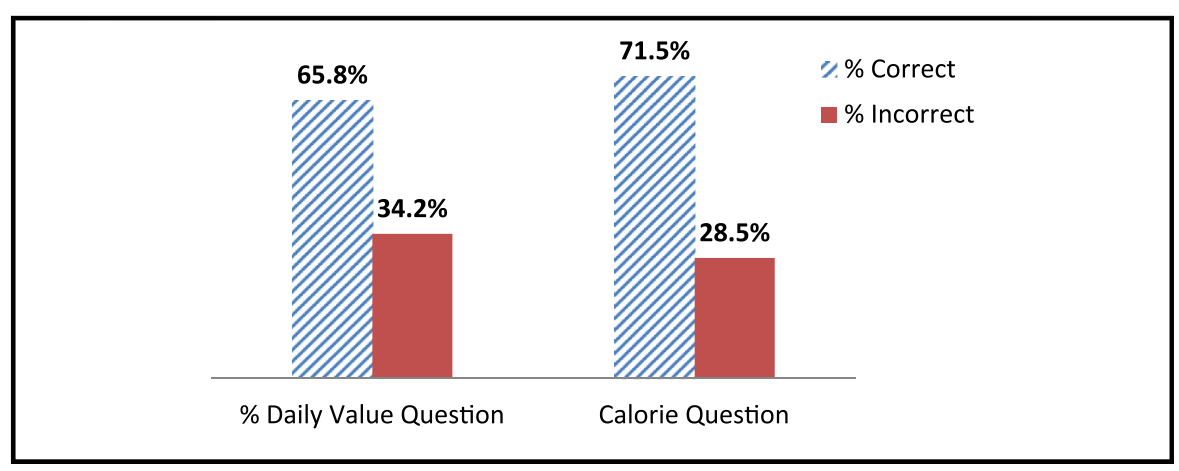

Figure 2. Proportion of participants who correctly and incorrectly answered the nutrition label questions $(n=637)$. 
Table 2. Logistic Regression Model Examining Correlates of Correctly Estimating Calorie and Percent Daily Value Amounts $(n=639)$

\begin{tabular}{|c|c|c|c|c|c|c|}
\hline & & Calorie Amount & & & Daily Value Amou & \\
\hline & $\begin{array}{l}\text { Odds } \\
\text { Ratio }\end{array}$ & $\begin{array}{l}\text { 95\% Confidence } \\
\text { Interval }\end{array}$ & $\boldsymbol{P}$ & $\begin{array}{l}\text { Odds } \\
\text { Ratio }\end{array}$ & $\begin{array}{l}\text { 95\% Confidence } \\
\text { Interval }\end{array}$ & $\boldsymbol{P}$ \\
\hline $\begin{array}{l}\text { Gender } \\
\quad \text { Male (reference) vs female }\end{array}$ & 1.33 & $0.92-1.93$ & .13 & 1.05 & $0.74-1.50$ & .79 \\
\hline $\begin{array}{l}\text { Age, y } \\
\text { 18-24 (reference) vs 25-34 } \\
\text { 18-24 (reference) vs 35-64 } \\
18-24 \text { (reference) vs } \geq 65 \\
\geq 65 \text { (reference) vs } 25-34 \\
\geq 65 \text { (reference) vs 35-64 } \\
\text { 25-34 (reference) vs 35-64 }\end{array}$ & $\begin{array}{l}1.32 \\
0.55 \\
0.29 \\
4.58 \\
1.91 \\
0.42\end{array}$ & $\begin{array}{l}0.66-2.64 \\
0.32-0.94 \\
0.15-0.54 \\
2.30-9.13 \\
1.18-3.10 \\
0.23-.77\end{array}$ & $\begin{array}{r}<.001 \\
.44 \\
.03 \\
<.001 \\
<.001 \\
.009 \\
.005\end{array}$ & $\begin{array}{l}0.87 \\
0.95 \\
0.52 \\
1.65 \\
1.81 \\
1.10\end{array}$ & $\begin{array}{l}0.47-1.60 \\
0.57-1.58 \\
0.29-0.97 \\
0.89-3.07 \\
1.11-2.97 \\
0.65-1.85\end{array}$ & $\begin{array}{l}.10 \\
.65 \\
.84 \\
.04 \\
.11 \\
.02 \\
.74\end{array}$ \\
\hline $\begin{array}{l}\text { Education } \\
\text { Low (reference) vs middle } \\
\text { Low (reference) vs high } \\
\text { High (reference) vs middle }\end{array}$ & $\begin{array}{l}2.15 \\
2.00 \\
1.07\end{array}$ & $\begin{array}{l}1.34-3.43 \\
1.09-3.70 \\
0.66-1.76\end{array}$ & $\begin{array}{l}.006 \\
.001 \\
.03 \\
.78\end{array}$ & $\begin{array}{l}2.68 \\
4.00 \\
0.67\end{array}$ & $\begin{array}{l}1.69-4.23 \\
2.15-7.45 \\
0.40-1.11\end{array}$ & $\begin{array}{l}<.001 \\
<.001 \\
<.001 \\
.12\end{array}$ \\
\hline $\begin{array}{l}\text { Income } \\
\quad \leq \$ 39,999 \text { (reference) vs } \$ 40,000-\$ 79,999 \\
\quad \leq \$ 39,999 \text { (reference) vs } \geq \$ 80,000 \\
\$ 40,000-\$ 79,999 \text { (reference) vs } \geq \$ 80,000\end{array}$ & $\begin{array}{l}2.05 \\
2.36 \\
1.15\end{array}$ & $\begin{array}{l}1.27-3.29 \\
1.36-4.08 \\
0.65-2.04\end{array}$ & $\begin{array}{l}.003 \\
.003 \\
.002 \\
.63\end{array}$ & $\begin{array}{l}1.78 \\
2.26 \\
1.27\end{array}$ & $\begin{array}{r}1.14-2.78 \\
1.34-3.80 \\
.74-2.18\end{array}$ & $\begin{array}{l}.008 \\
.01 \\
.002 \\
.38\end{array}$ \\
\hline $\begin{array}{l}\text { Ethnicity } \\
\text { White (reference) vs other }\end{array}$ & 0.74 & $0.49-1.13$ & .16 & 0.50 & $0.34-0.74$ & .001 \\
\hline $\begin{array}{l}\text { Body mass index } \\
\text { Underweight (reference) vs normal weight } \\
\text { Underweight (reference) vs overweight } \\
\text { Underweight (reference) vs obese } \\
\text { Obese (reference) vs normal weight } \\
\text { Obese (reference) vs overweight } \\
\text { Overweight (reference) vs normal weight }\end{array}$ & $\begin{array}{l}1.61 \\
2.25 \\
2.85 \\
0.56 \\
0.79 \\
0.71\end{array}$ & $\begin{array}{l}0.42-6.19 \\
0.57-8.95 \\
0.70-11.59 \\
0.34-0.93 \\
0.48-1.31 \\
0.46-1.11\end{array}$ & $\begin{array}{l}.10 \\
.49 \\
.25 \\
.14 \\
.24 \\
.36 \\
.13\end{array}$ & $\begin{array}{l}1.95 \\
1.28 \\
1.36 \\
1.43 \\
0.94 \\
1.52\end{array}$ & $\begin{array}{l}0.51-7.47 \\
0.33-5.00 \\
0.34-5.43 \\
0.89-2.29 \\
0.59-1.50 \\
1.00-2.33\end{array}$ & $\begin{array}{l}.19 \\
.33 \\
.72 \\
.66 \\
.14 \\
.80 \\
.05\end{array}$ \\
\hline
\end{tabular}

Note: Bolded values indicate $P<.05$, which is considered significant.

only variable that was significant $(P=$ .03). Specifically, participants who indicated that they looked at nutrition facts or calories on labels were significantly more likely to correctly answer the calorie question vs participants who did not look at any information on labels $(P=.01$; odds ratio, 2.59 ; 95\% confidence interval, 1.25-5.35).

A separate logistic regression model was run to identify sociodemographic correlates of correctly answering the $\%$ DV question (Table 2). Education, income, and ethnicity were significantly associated with correctly answering the \% DV question. Participants who had middle or high education levels were significantly more likely to correctly answer the \% DV question vs participants who had lower education levels. Higher income was also associated with correct responses; individuals who had an annual household income, before taxes, of $\$ 40,000-\$ 79,999$, and $\geq$ $\$ 80,000$, were significantly more likely to answer the \% DV question correctly vs those who made $\leq$ $\$ 39,999$. With respect to ethnicity, Caucasian participants had a significantly higher likelihood of answering the \% DV question correctly. No significant differences were observed for gender, age, and BMI.

In the second block of the logistic regression, none of the added variables was significant and all of the sociodemographic variables entered in block 1 remained significant.

\section{DISCUSSION}

Approximately two thirds of participants correctly answered both the calorie and DV questions, with slightly fewer people able to correctly answer the DV question. The current results are similar to previous research conducted in Canada. ${ }^{6}$ A national survey conducted in 2008 found that $80 \%$ of Canadians were confident in their understanding of nutrition labels, which is somewhat higher than the results found in the current study. ${ }^{6}$ This indicates that although people report high comprehension, actual understanding on nutrition label tasks may be somewhat lower. The findings are also broadly similar with an international review of the understanding of nutrition labeling by Cowburn and Stockley, 4 in which where 19 studies found that people have issues converting nutrition label information. Converting serving sizes is a difficult task for many people, which was also reflected in the findings of the current study, because fewer participants correctly answered the DV question. The nutrition label used in the NVS tool displays rounded 
numbers for the calorie amounts (250 calories), serving sizes ( $1 / 2$ cup), and $\%$ daily amounts (20\%) that are likely to be easier to use than the numbers commonly encountered in nutrition labels. Therefore, the current study may actually overestimate the proportion of respondents who can accurately use and convert nutrition numbers.

With respect to sociodemographic correlates of health literacy, lower income and education were significantly associated with incorrectly answering both the NVS calorie question and the DV question. In addition, older age and non-white ethnicity were significantly associated with incorrect responses to the calorie and DV questions, respectively. These findings were broadly consistent with previous research indicating that comprehension of nutrition labels-and health literacy, more generally-is lower among more disadvantaged individuals and older individuals. ${ }^{4,5,9,14,15}$ The findings on ethnicity, similar to previous studies using the NVS tool, indicate lower health literacy among minority groups. ${ }^{14,15}$ As with research conducted by Shah et al, ${ }^{15}$ BMI was not significantly associated with health literacy in the current study. Relatively few studies have examined the association between the NVS tool with BMI, and additional research is required.

There were several limitations to the current study. First, participants were recruited from the KitchenerWaterloo region, which is not representative of the entire Canadian population, as described previously. ${ }^{12}$ In addition, only individuals who could both speak and write in English were recruited. Under-representation of non-English-speaking and lower socioeconomic status individuals likely overestimated levels of health literacy in the broader population. The survey participants were asked questions regarding self-rated diet and health, which may not have been an accurate representation of actual diet and health. Consequently, the null findings for these variables may have resulted from participants over-reporting the quality of their health and diet. Therefore, future studies should include objective measures of diet and health as opposed to self-report measures. Finally, only 2 of the 6 NVS questions were administered in the current study, and therefore, these items may not be fully representative of the entire NVS measure as an overall measure of nutrition label literacy. More research on the understanding of nutrition labels in Canada using all 6 NVS questions is required to assess health literacy in a more comprehensive manner.

\section{IMPLICATIONS FOR RESEARCH AND PRACTICE}

Health literacy remains a major barrier for Canadians in understanding nutrition labels. The current findings indicate that a substantial minority of Canadians are not able to apply basic nutrition information presented on government-mandated labels, under study conditions that are likely to overestimate comprehension. In addition, comprehension was lowest among the most disadvantaged sociodemographic groups. Overall, the study highlights the importance of developing nutrition labels that are easier to understand and apply. ${ }^{7,14}$ These findings have implications for prepackaged food labeling, as well as menu labeling policies, such as the Food and Drug Administration regulations that require calorie amounts to be displayed on menus in chain restaurants in the United States. ${ }^{16}$ Previous research has highlighted the potential for the addition of non-numerical information on food labels (such as color-coded categories or qualitative descriptors), which may improve comprehension for individuals with low literacy. For example, various front-of-package designs have been found to improve label understanding in individuals with low health literacy. ${ }^{5}$

\section{ACKNOWLEDGMENTS}

This work was supported by a grant from the Canadian Cancer Society Research Institute. Additional support was provided by the Propel Centre for Population Health Impact, a Canadian Institutes of Health Research New Investigator Award (DH), and a Canadian Cancer Society Research
Institute Junior Investigator Award (DH).

\section{REFERENCES}

1. Obesity and overweight: facts. World Health Organization. http://www .who.int/mediacentre/factsheets/fs311/ en/index.html. Accessed July 2, 2013.

2. Obesity in Canada. Public Health Agency of Canada. http://www.phacaspc.gc.ca/hp-ps/hl-mvs/oic-oac/indexeng.php. Accessed July 2, 2013.

3. Nutrition Labelling. Health Canada. http://www.hc-sc.gc.ca/fn-an/labeletiquet/nutrition/reg/index-eng.php. Accessed July 2, 2013.

4. Cowburn G, Stockley L. Consumer understanding and use of nutrition labelling: a systematic review. Public Health Nutr. 2005;8:21-28.

5. Campos S, Doxey J, Hammond D. Nutrition labels on pre-packaged foods: a systematic review. Public Health Nutr. 2011;14:1496-1506.

6. Tracking nutrition trends VII. Canadian Council of Food and Nutrition. http://www.cfdr.ca/Downloads/CCFNdocs/C1180-TNT-VII-FINAL-REPO RT-full-report-Sept-1.aspx. Accessed July 16, 2013.

7. Drichoutis AC, Lazaridis P, Nayga RMJr. On consumers' valuation of nutrition information. Bull Econ Res. 2009;61:223-247.

8. The Strategic Counsel. Canadians' understanding and use of the nutrition facts table: baseline national survey results. Ottawa, Ontario, Canada: Health Canada; 2011.

9. Chen X, Jahns L, Gittelsohn J, Wang Y. Who is missing the message? Targeting strategies to increase food label use among US adults. Public Health Nutr. 2012;15:760-772.

10. Weiss BD, Mays MZ, Martz W, et al. Quick assessment of literacy in primary care: the Newest Vital Sign. Ann Fam Med. 2005;3:514-522.

11. Osborn CY, Weiss BD, Davis TC, et al. Measuring adult literacy in health care: performance of the Newest Vital Sign. Am J Health Behav. 2007;31:36-46.

12. Goodman S, Hammond D, Hanning RM, Sheeska J. The impact of adding frontof-package sodium content labels to grocery products: an experimental study. Public Health Nutr. 2012;16: 383-391.

13. Canadian guidelines for body weight classification in adults. Health Canada. http://www.hc-sc.gc.ca/fn-an/nutrition/ 
772 Sinclair et al

weights-poids/guide-ld-adult/qa-qr-pubeng.php. Accessed July 2, 2013.

14. Zoellner J, You W, Connell C, et al. Health literacy is associated with health eating index scores and sugarsweetened beverage intake: findings from the Rural Lower Mississippi

Journal of Nutrition Education and Behavior • Volume 45, Number 6, 2013

Delta. J Am Diet Assoc. 2011;111: 1012-1020.

15. Shah LC, West P, Bremmeyr K, Savoy-Moore RT. Health literacy instrument in family medicine: the "Newest Vital Sign" ease of use and correlates. J Am Board Fam Med. 2010;23:195-203.
16. FDA proposes draft menu and vending machine labeling requirements, invites public to comment on proposals. United States Food and Drug Administration. http://www.fda.gov/NewsEvents/News room/PressAnnouncements/ucm249471. htm. Accessed April 12, 2013. 